\title{
Live attenuated influenza viruses produced in a suspension process with avian AGE1.CR.pIX cells
}

\author{
Verena Lohr ${ }^{1 *}$, Yvonne Genzel ${ }^{1}$, Ingo Jordan², Dietmar Katinger ${ }^{3}$, Stefan Mahrr ${ }^{1,4}$, Volker Sandig² and Udo Reichl,
}

\begin{abstract}
Background: Current influenza vaccines are trivalent or quadrivalent inactivated split or subunit vaccines administered intramuscularly, or live attenuated influenza vaccines (LAIV) adapted to replicate at temperatures below body temperature and administered intranasally. Both vaccines are considered safe and efficient, but due to differences in specific properties may complement each other to ensure reliable vaccine coverage. By now, licensed LAIV are produced in embryonated chicken eggs. In the near future influenza vaccines for human use will also be available from adherent MDCK or Vero cell cultures, but a scalable suspension process may facilitate production and supply with vaccines.

Results: We evaluated the production of cold-adapted human influenza virus strains in the duck suspension cell line AGE1.CR.pIX using a chemically-defined medium. One cold-adapted A (H1N1) and one cold-adapted $B$ virus strain was tested, as well as the reference strain A/PR/8/34 (H1N1). It is shown that a medium exchange is not required for infection and that maximum virus titers are obtained for $1 \times 10^{-6}$ trypsin units per cell. $1 \mathrm{~L}$ bioreactor cultivations showed that $4 \times 10^{6}$ cells $/ \mathrm{mL}$ can be infected without a cell density effect achieving titers of $1 \times 10^{8}$ virions $/ \mathrm{mL}$ after $24 \mathrm{~h}$.

Conclusions: Overall, this study demonstrates that AGE1.CR.pIX cells support replication of LAIV strains in a chemically-defined medium using a simple process without medium exchanges. Moreover, the process is fast with peak titers obtained $24 \mathrm{~h}$ post infection and easily scalable to industrial volumes as neither microcarriers nor medium replacements are required.
\end{abstract}

Keywords: Live attenuated influenza virus, Influenza vaccine production, Suspension cell culture, Cell density effect, AGE1.CR.pIX

\section{Background}

Annual vaccination is the most efficient way to reduce the immense number of 3-5 million cases of severe illness or death due to influenza virus infections. Different vaccine types have been developed and are being deployed for this purpose over the past $60-70$ years. The most common type is the trivalent influenza vaccine (TIV) derived from inactivated whole virus. TIVs are injected intramuscularly or intradermal. They have a favorable safety profile and induce reliable protective immunity against viral strains which are similar to those present in the vaccine. However, because efficacy against new virus variants can be low, the composition of the vaccine has to be carefully

\footnotetext{
*Correspondence: lohr@mpi-magdeburg.mpg.de

1 Max Planck Institute for Dynamics of Complex Technical Systems, Sandtorstr. 1, 39106, Magdeburg, Germany

Full list of author information is available at the end of the article
}

predicted for each influenza season [1]. Another type of influenza vaccines is the live attenuated influenza vaccine (LAIV) comprising virus strains that are adapted to replication at temperatures below the human body temperature. LAIVs are administered through a nasal spray mimicking a natural infection of the mucosal cells of the nasopharynx. However, these viruses cannot replicate at non-permissive temperatures present in the lower respiratory tract and lungs. Due to the attenuated infection in the upper respiratory tract, these vaccines induce not only strain specific immunity but also $\mathrm{T}$ cell responses that may be cross-reactive and thus contribute to protection against a wider spectrum of influenza $\mathrm{A}$ and $B$ strains [2-4]. The only approved LAIVs are FluMist ${ }^{\circledR}$ (MedImmune) for the US and Russian market and, since 2011 , the European analogue Fluenz ${ }^{\circledR}$, both produced in an egg-based process [5]. As opposed to parenteral inactivated

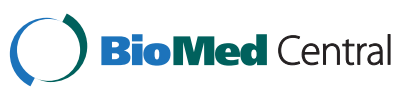


vaccines, the downstream processing requirements are less stringent and thus less expensive for mucosal live virus vaccines. Also for this reason, the WHO encouraged to extend the manufacturing of LAIVs as part of the global pandemic influenza action plan [6].

Production of LAIVs has so far been investigated in three host systems: chicken eggs [7], adherent MDCK [8-10] or adherent Vero cells [11-13]. Because properties such as replication kinetics, viral RNA synthesis and protein expression appear to be comparable in cell culture- or egg-derived virus strains [14], both have been approved for the production of vaccines for human use. However, there are inherent limitations associated with the process design related to the decision for a specific host system, being more or less pronounced for one or the other. Scalability, for example, is impaired significantly for adherent cell lines cultivated in static or microcarrier systems. The use of suspension-adapted cell lines such as MDCK and Vero could overcome this limitation. These cells have been adapted to growth in suspension by several groups [15-18] and by the industry where they are already used in vaccine manufacturing [19]. Other suspension cell lines useful for influenza vaccine production are PER.C6 [20], HEK293 [21], EB66 [22] or AGE1.CR.pIX (in the following: CR.pIX) [23,24].

The CR.pIX cell line has been generated specifically for production of modern vaccines. Its derivation and identity is fully documented and genetic stability was shown for at least 90 passages [25]. As required by regulatory authorities, the absence of adventitious agents was confirmed via extensive testing of CR.pIX cell banks by a spectrum of methods such as transmission electron microscopy against microbial structures; diagnostic PCR reactions against specific avian, bovine and porcine agents; in vitro assays with various sentinel cell lines for any cytopathic effects; in vivo assays in different animal species for any signs of infection or induction of antibodies; quantitative fluorescent product enhanced reverse transcriptase (QFPERT) assay and co-cultivation to detect endogenous or exogenous retroviral contamination; and inoculation of cell line material into various agars and broths to test against mycoplasma and other bacteria. With regards to process technology, this cell line proliferates in suspension in a chemically-defined medium and has been shown to support influenza A virus replication. Moreover, CR.pIX cells are expected to be susceptible for a broad spectrum of virus subtypes and strains as they display both $\alpha 2,3-$ and $\alpha 2,6$-linked sialic acids as surface membrane receptors [26].

For the design of vaccine production processes using a new host cell, studies concerning crucial infection parameters like trypsin activity and multiplicity of infection (moi) are necessary. In addition, the cell concentration at time of infection (CCI) has been reported to be important for adenovirus, baculovirus and influenza virus production [21,27-30]. These studies demonstrated that above a certain CCI, the cell-specific virus productivity drops substantially, what is called the "cell density effect". All studies related to this topic indicate that the reasons for the cell density effect are highly dependent on the production system (mainly virus species, host cell line and medium) and thus cannot be generalized. Explanations for this effect include depletion of nutrients or accumulation of inhibiting substances [30]. Also, activity or availability of host cell factors required for virus replication may change with the cell cycle [31] or with metabolic shifts [28,31] at higher cell densities. As an example, for production of influenza virus typically $1-2 \times 10^{6}$ cells $/ \mathrm{mL}$ are used, but with fed-batch or perfusion strategies exhaustion of medium components and influence of inhibiting substances can be avoided and high-yield infections of $1 \times 10^{7}$ cells $/ \mathrm{mL}$ have been demonstrated [32,33]. The aim of overcoming the cell density effect is to maintain or even increase the cell-specific productivity in order to improve process productivity, i.e. to increase the vaccine doses which can be harvested per reactor volume.

In this work, we produced human LAIV strains in a chemically-defined medium using CR.pIX cells. One cold-adapted $(c a)$ influenza A strain (H1N1), one ca influenza B strain as well as the reference strain A/PR/8/34 (H1N1; not cold-adapted) were propagated. After adapting the virus strains to CR.pIX cells we confirmed temperature sensitivity and identified best cultivation conditions such as medium supply and trypsin activity for successful infection in small-scale scouting experiments. Subsequently, batch bioreactor cultivations were performed to demonstrate that cultures can be productively infected at a CCI of $4 \times 10^{6}$ cells $/ \mathrm{mL}$ without any medium exchange, doubling the CCI that has been used previously with CR.pIX cells $\left(2 \times 10^{6}\right.$ cells $\left./ \mathrm{mL}\right)$ [23]. Only at higher CCI a cell density effect was observed when infecting without a medium exchange. In all experiments, high titers and fast replication dynamics have been achieved demonstrating a chemically-defined suspension production process for influenza LAIV strains.

\section{Results}

\section{The chemically-defined medium CD-U2 supports direct infection}

Experimental data on influenza virus production in CR.pIX cells is available only for cultures in serum-free proliferation medium containing hydrolysates [23]. However, to improve proliferation of CR.pIX cells and to reduce risk of lot-to-lot inconsistencies due to variable hydrolysate composition, a chemically-defined medium (CD-U2) has been developed specifically for this cell line [25]. As a reference for the 
evaluation of cold-adapted virus propagation, and to test virus stability and the requirement for a medium exchange, replication of the human influenza virus strain $\mathrm{H} 1 \mathrm{~N} 1$ $\mathrm{A} / \mathrm{PR} / 8 / 34$ was investigated first. This strain is included regularly in similar studies and titers obtained with $\mathrm{CR}$. pIX cells therefore can be compared to other producer cells.

CR.pIX cells were infected with A/PR/8/34 without medium exchange, after a partial medium exchange (half of the culture), or after a complete medium exchange. Infection took place at a CCI of $2 \times 10^{6}$ cells $/ \mathrm{mL}$ that was reached approximately two days after culture inoculation.

HA yields and $\mathrm{TCID}_{50}$ titers differed slightly using the three medium exchange strategies (Figure 1) with a trend towards lower titers when a medium exchange was applied. The HA yield reached a plateau of 2.0-2.3 $\log _{10} \mathrm{HA}$ units $/ 100 \mu \mathrm{L}$ at $24 \mathrm{~h}$ post infection (hpi) and remained stable until 72 hpi (later data points not shown). TCID $_{50}$ titers reached a maximum at $24 \mathrm{hpi}$, but were less stable than the HA yield, decreasing about $1 \log$ unit in $48 \mathrm{~h}$. The maximum TCID $_{50}$ of $1.3 \times 10^{8}$ virions/mL was obtained in cultures which have been infected directly and lowest TCID $_{50}$ was observed after exchanging half of the growth medium. None of the cultures exhibited limiting substrate levels at time of infection, which was confirmed with metabolite concentration measurements (data not shown). From these results we concluded that a medium exchange is not required and that $\mathrm{CD}-\mathrm{U} 2$ supports stable $\mathrm{HA}$ virus yields and good TCID 50 titers at a CCI of $2 \times 10^{6}$ cells $/ \mathrm{mL}$.
Temperature sensitivity of LAIV strains is maintained after adaptation

Influenza virus has a broad host range and can shuttle between mammalian and avian cells. However, virus replication dynamics and maximum titers may be impaired by a sudden shift to a new cell substrate and may be improved by serial passages of the virus in the new host cell line. For this reason, the LAIV strains $\mathrm{A} /$ Singapore and $\mathrm{B} / \mathrm{Vi}$ enna (for details on these strains see materials \& methods section) were adapted to CR.pIX cells to generate working seed viruses with high titers. At the same time, care was taken to achieve this with a minimum number of passages (maximum 3) to minimize the potential for reversion to replication at non-permissive temperatures.

After adaptation to CR.pIX cells, the A/Singapore and B/Vienna strain had, respectively, 1.1 and $1.4 \log _{10}$ increased maximum $\mathrm{TCID}_{50}$ titers. The chosen seed viruses were from passage 3 for the A/Singapore strain, harvested at $28 \mathrm{hpi}$, and from passage 2 for the B/Vienna strain, harvested at $34 \mathrm{hpi}$. Overall, 5 (A/Singapore) and 6 days (B/Vienna) were needed to complete the adaptation to CR.pIX cells. The mentioned harvests were used as working seed viruses for all subsequent experiments.

Considering temperature sensitivity, we tested replication of both $\mathrm{ca}$ strains at $37^{\circ} \mathrm{C}$ before adaptation to CR.pIX cells and could not detect any virus titer, whereas virus propagation was successful at $33^{\circ} \mathrm{C}$ (Table 1). To test whether the required temperature sensitivity of LAIV strains was still present after the adaptation process, infection experiments were conducted at 33,37 and $40^{\circ} \mathrm{C}$. The B strain was highly sensitive to non-permissive temperature as no viral activity

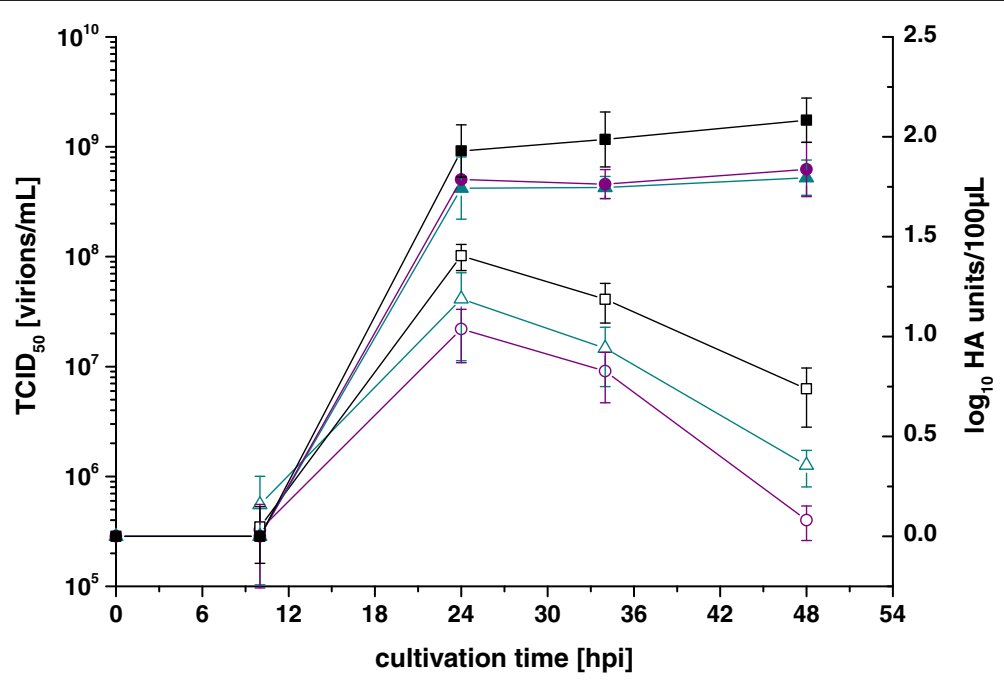

Figure $1 \mathrm{TCID}_{50}$ titers (open symbols) and $\mathrm{HA}$ yields (closed symbols) from infections performed with different medium exchange strategies. CR.plX cells were infected with influenza strain A/PR/8/34 in shaker flasks at a CCI of $2 \times 10^{6} \mathrm{cells} / \mathrm{mL}$ and $1 \times 10^{-6}$ units trypsin per cell. Three strategies were performed: infection without medium exchange $(\mathbf{\bullet}$, black), after a medium exchange $(\boldsymbol{\Lambda}$, cyan) and after the exchange of $50 \%$ of the medium $(\bullet$, purple). Error bars indicate standard deviation of three independent cultures. 
Table 1 Temperature sensitivity of A/Singapore and B/ Vienna viruses in CR.pIX cells

\begin{tabular}{llll}
\hline Maximum $\mathrm{TCID}_{\mathbf{5 0}}$ titers [virions $\left./ \mathbf{m L}\right]^{*}$ & $\mathbf{3 3 ^ { \circ } \mathbf { C }}$ & $\mathbf{3 7 ^ { \circ } \mathbf { C }}$ & $\mathbf{4 0}^{\circ} \mathbf{C}$ \\
\hline Before adaptation to CR.plX cells & & & \\
A/Singapore & $1.3 \times 10^{8}$ & 0 & $-^{\#}$ \\
B/Vienna & $1.8 \times 10^{5}$ & 0 & - \\
After adaptation to CR.pIX cells & & & \\
A/Singapore & $2.4 \times 10^{8}$ & $1.8 \times 10^{6}$ & 0 \\
B/Vienna & $3.2 \times 10^{6}$ & 0 & - \\
\hline
\end{tabular}

${ }^{*}$ Maximum titers of CR.pIX cells infected in T-flasks at a CCI of $2 \times 10^{6}$ cells $/ \mathrm{mL}$ and with $1 \times 10^{-6}$ units trypsin per cell.

"not determined.

was determined at $37^{\circ} \mathrm{C}$, obviating further examination of replication at $40^{\circ} \mathrm{C}$. The $\mathrm{A} /$ Singapore strain produced about 40 times less active virus particles at $37^{\circ} \mathrm{C}$ compared to $33^{\circ} \mathrm{C}$. At $40^{\circ} \mathrm{C}$, no active particles were detected. These results indicate that both working virus seeds exhibit the expected temperature sensitivity.

\section{Optimization of trypsin activity}

LAIV strains replicate at $33^{\circ} \mathrm{C}$ and the activity of trypsin (initially optimized for replication at $37^{\circ} \mathrm{C}$ ) is expected to be slightly reduced at $33^{\circ} \mathrm{C}$ [34]. To test whether this reduction requires higher amounts of trypsin for propagation of cold-adapted virus strains, we tested different trypsin activities with A/Singapore and B/Vienna (Figure 2). When using $1 \times 10^{-6}$ units/cell (standard concentration for $\mathrm{A} / \mathrm{PR} / 8 / 34$ propagation), maximum $\mathrm{TCID}_{50}$ values were measured at $48 \mathrm{hpi}$. An increase of the trypsin activity to $5 \times 10^{-6}$ units/cell or even $10 \times 10^{-6}$ units/cell reduced the titers of A/Singapore and B/Vienna. Infections without trypsin addition did not produce any infectious virus particles. Thus, without further adaptation of this parameter, $1 \times 10^{-6}$ units trypsin per cell was found to support best the replication of A/Singapore $\left(2.4 \times 10^{8}\right.$ virions $/ \mathrm{mL})$ and $\mathrm{B} /$ Vienna $\left(3.2 \times 10^{6}\right.$ virions $\left./ \mathrm{mL}\right)$.

\section{Cell density effect in bioreactor cultivations}

Whether the $c a$ strains can be produced in bioreactors is an important test towards suitability of LAIV strain production for seasonal or pandemic vaccines in the CR.pIX suspension cells. Focusing on the A/Singapore strain, we therefore performed experiments in a benchtop stirred tank bioreactor system to test the scale-up potential. The cell density effect was evaluated by varying the cell concentration at time of infection with the aim to identify the highest $\mathrm{CCI}$ that can be used without reduction of cell-specific productivity. One problem for infection at high CCI could be the release and accumulation of trypsin inhibitors during the growth phase. We therefore also tested if a higher trypsin activity or a medium feed at high CCI can rescue productivity. Six bioreactor runs were performed with infections at $4 \times 10^{6}$ cells $/ \mathrm{mL}$ (three days batch growth), $6 \times 10^{6}$ cells $/ \mathrm{mL}$ (five days batch growth) and $8 \times$ $10^{6}$ cells/mL (six days batch growth) (Figure 3A). Exact cell concentrations together with added trypsin and medium are summarized in Table 2 .

At the lowest CCI $\left(4 \times 10^{6}\right.$ cells $\left./ \mathrm{mL}\right)$, cell-specific virus yields of 15 (CCI_4_1) and 19 active virions/cell (CCI_4_2) were obtained. Infection of the intermediate group with a CCI of about $6 \times 10^{6}$ cells $/ \mathrm{mL}$ led to reduced titers $\left(1 \times 10^{7}\right.$ virions $/ \mathrm{mL}$ for both cultures) compared to the lowest CCI $\left(1 \times 10^{8}\right.$ virions/mL $)$ and, correspondingly, reduced cell-specific productivities (1-2 virions/ cell). Using a high CCI of about $8 \times 10^{6}$ cells $/ \mathrm{mL}$ resulted in titers of $8 \times 10^{6}$ virions $/ \mathrm{mL}$ and $6 \times 10^{7}$ virions $/ \mathrm{mL}$, respectively, and hence also low cell-specific virus
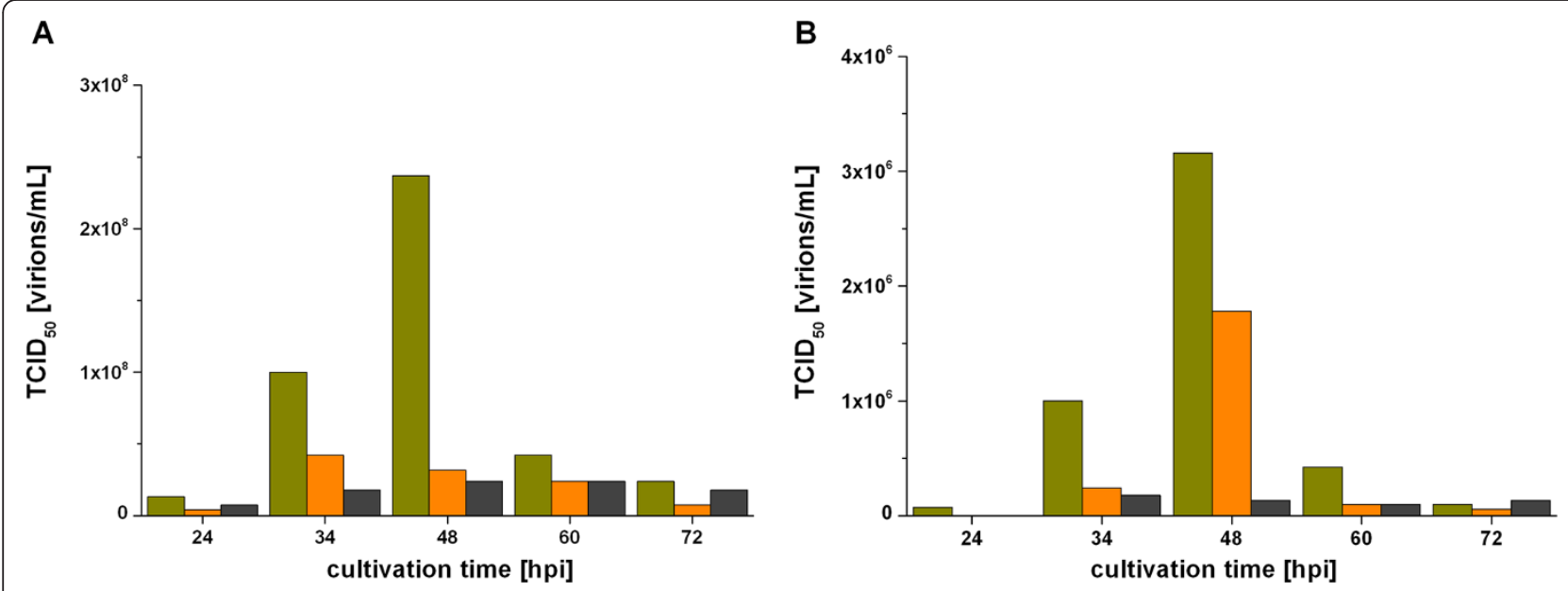

Figure 2 Optimization of trypsin activity used for the infection of CR.pIX cells with LAIV strains A/Singapore (A) and B/Vienna (B).

Tested trypsin activities were $1 \times 10^{-6}$ units/cell (green), $5 \times 10^{-6}$ units/cell (orange) and $10 \times 10^{-6}$ units/cell (black). Cells were infected in T-flasks at a $\mathrm{CCl}$ of $2 \times 10^{6}$ cells $/ \mathrm{mL}$ without applying a medium exchange. 

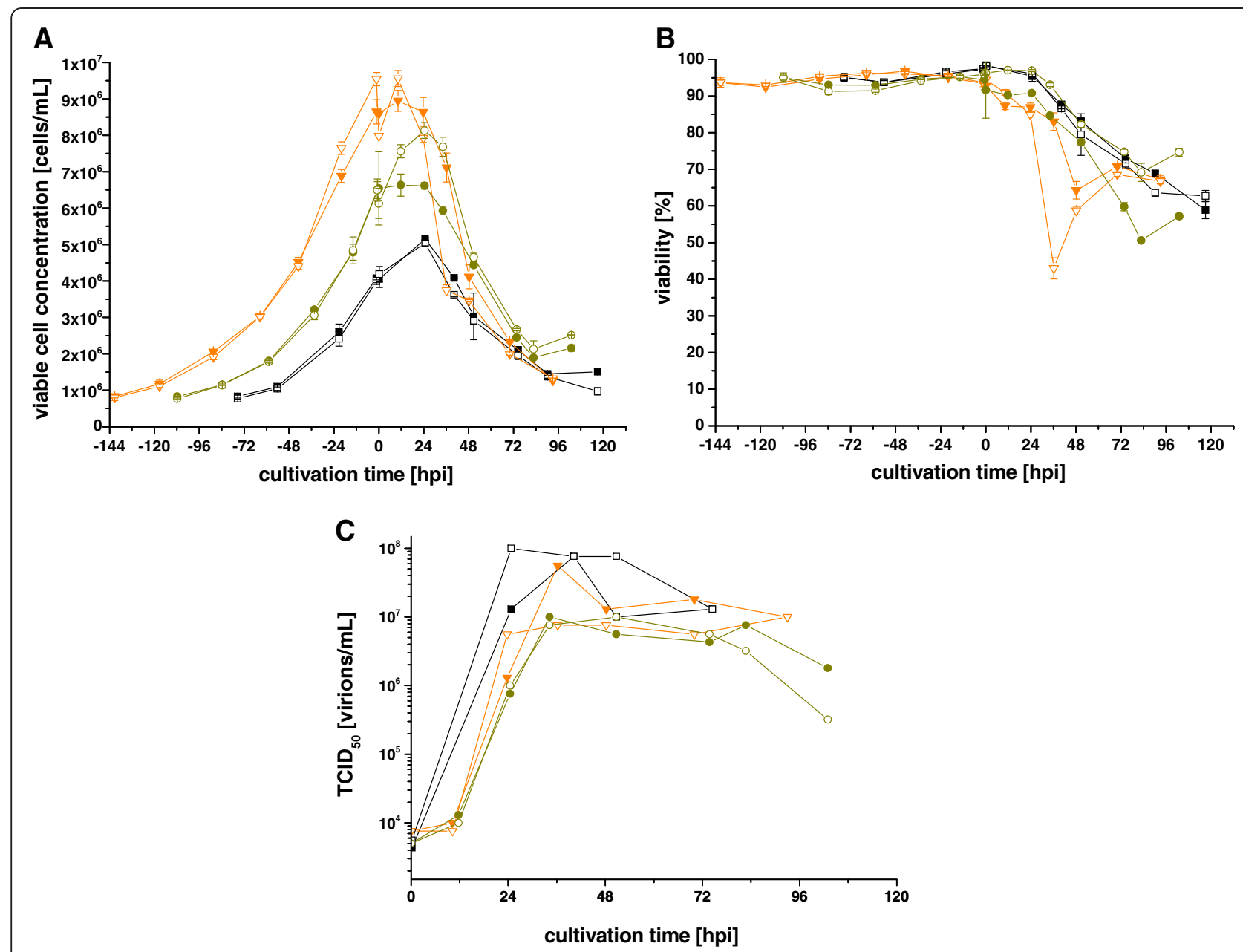

Figure 3 Infection of CR.pIX cells with the LAIV strain A/Singapore at different cell concentrations at time of infection. Viable cell concentrations (A), viabilities (B) and $\mathrm{TCID}_{50}$ titers $(\mathbf{C})$ of bioreactor cultivations are shown. Cells were infected with parameters summarized in

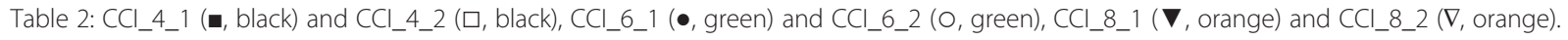
After the cell growth phase at $37^{\circ} \mathrm{C}$, bioreactor temperature was controlled at $33^{\circ} \mathrm{C}$ during the infection phase. Error bars for viable cell concentrations and viabilities indicate standard deviations of triplicate measurements.

yields of 6 and 2 virions/cell, respectively. This shows that neither the titer nor the productivity was rescued when applying a higher trypsin activity $\left(10 \times 10^{-6}\right.$ units/cell) or a medium addition $(200 \mathrm{~mL})$ at the highest CCI. For all cultures, viability at time of infection was above $90 \%$ (Figure 3B), showing that cells were not impaired due to extension of the growth phase. Thus, a cell density effect, i.e. a loss in cell-specific virus productivity, was observed at CCI above $4 \times 10^{6}$ cells $/ \mathrm{mL}$.
A comparison to shaker flask experiments (which resulted in 15-20 virions/cell, data not shown) confirmed that scale-up to a benchtop bioreactor did not reduce virus titers or productivities at a CCI of $4 \times 10^{6}$ cells $/ \mathrm{mL}$. From these results we conclude that a CCI of up to $4 \times 10^{6}$ cells $/ \mathrm{mL}$ can be used for virus production without the requirement for a medium exchange and, most importantly, without loss of cell-specific productivity.

Table 2 Bioreactor cultivations performed with the LAIV strain A/Singapore

\begin{tabular}{lllllrl}
\hline & CCl_4_1 & CCl_4_2 & CCl_6_1 & CCl_6_2 & CCl_8_1 & CCl_8_2 \\
\hline CCl $[$ viable cells/mL] & $4.2 \times 10^{6}$ & $4.1 \times 10^{6}$ & $6.5 \times 10^{6}$ & $6.1 \times 10^{6}$ & $7.4 \times 10^{6}$ & $8.0 \times 10^{6}$ \\
Trypsin conc. [units/cell] & $10 \times 10^{-6}$ & $1 \times 10^{-6}$ & $1 \times 10^{-6}$ & $1 \times 10^{-6}$ & $10 \times 10^{-6}$ & $10 \times 10^{-6}$ \\
Feed & - & - & - & - & - & $200 \mathrm{~mL}$ \\
\hline
\end{tabular}

CR.pIX cell cultures were infected at different $\mathrm{CCl}$ and trypsin activities. Upon infection, the temperature was reduced to $33^{\circ} \mathrm{C}$ for virus propagation. 


\section{Discussion}

Increasing and unmet demand for vaccination against seasonal and pandemic influenza virus is a strong motivation for exploring additional means in vaccine manufacturing. Currently, most inactivated and the live attenuated influenza vaccines are manufactured in embryonated chicken eggs, an established technology but associated with demanding logistics, risks of allergic reactions and difficulties in scalability. Therefore, some influenza vaccine manufacturers have developed new production processes for influenza vaccines in cell culture (Vero and MDCK cells), although LAIVs are still exclusively produced in eggs [35]. In particular, the use of continuous cell lines adapted to growth in suspension has the potential for large scale production in closed systems using a comparatively simple generic process. We therefore investigated replication of influenza virus in the CR.pIX cell line, which is specifically created and designed for vaccine manufacture and is adapted to proliferate in chemically-defined media. Generally, CR. pIX cells show a good proliferation performance with growth rates in the range of 0.016 and $0.023 \mathrm{~h}^{-1}$ (derived from the exponential growth phase of the bioreactor cultivations shown in Figure 3). After seven days, approximately $1 \times 10^{7}$ cells $/ \mathrm{mL}$ can be achieved in batch cultivation. In conjunction with a well-balanced medium (CD-U2), this leads to a short growth phase so that infections can be initiated soon after inoculation.

In the first part of our study we demonstrate that CR. pIX cells can produce influenza virus to high titers in shaker flasks. For the reference strain A/PR/8/34, TCID 50 titers of $1.3 \times 10^{8}$ virions $/ \mathrm{mL}$ were achieved, which is in a similar range $\left(10^{7}\right.$ to $10^{9}$ virions $\left./ \mathrm{mL}\right)$ reported for other cell lines $[19,35,36]$. The achieved HA titers (used to calculate the number of vaccine doses for inactivated virus vaccines) are about $2.0 \log \mathrm{HA}$ units/100 $\mu \mathrm{L}$ which is slightly lower than those normally obtained with conventional cells (MDCK or Vero cells) or new candidate cell lines (HEK293, PER.C6). Mostly, these are reported to propagate the $\mathrm{A} / \mathrm{PR} / 8 / 34$ influenza virus strain to titers of 3.0 to $3.6 \log \mathrm{HA}$ units $/ 100 \mu \mathrm{L}$ [21,35-37]. Generally, CR.pIX cells seem to generate the same $\mathrm{TCID}_{50}$ titers, but slightly lower HA titers and thus should in particular be considered for the production of LAIV strains. With a medium replacement at time of infection, we could not observe a titer increase and thus we conclude that a process without any medium exchange is possible in this system, a property which substantially simplifies a suspension process at industrial scales.

LAIV strains must have a temperature-sensitive and cold-adapted phenotype in order to be considered safe for use in human vaccination. Thus, we tested temperature sensitivity after adapting the $c a$ strains to CR.pIX cells.
The B/Vienna strain showed to be temperature-sensitive as no active virions were produced at $37^{\circ} \mathrm{C}$. The titer of A/Singapore was reduced about $1.5 \log$ at $37^{\circ} \mathrm{C}$ compared to $33^{\circ} \mathrm{C}(40 \%)$. This reduction is not as clear as for the B strain but expected from previous studies as the replication deficiency must be obvious only at 39 or $40^{\circ} \mathrm{C}$ for A strains [38]. Other studies have demonstrated a titer reduction of $20 \%$ at $37^{\circ} \mathrm{C}$ compared to the titer at $33^{\circ} \mathrm{C}$ [39] and of $2 \log$ units for the master donor strain $\mathrm{B} / \mathrm{Ann}$ Arbor/1/66 strain [40]. This range was also observed here. Testing the temperature sensitivity before and after adaptation to CR.pIX cells (restricted to 23 passages) confirmed the temperature-sensitive phenotype. Both $c a$ strains were pheno- and genotypically characterized for patent registration before reassortment and adaptation to CR.pIX cells [41], and it was shown that both cold-adapted strains carry several mutations compared to the wild type strains. For the A/Singapore strain there were 13 mutations with 8 of them coding for an amino acid exchange. For the $\mathrm{B} /$ Vienna strain 5 mutations were detected by sequencing with 3 of them coding for an amino acid exchange. Generally, sequencing of both strains could be of interest for follow-up studies considering mutations that occur during adaptation to the host cell line CR.pIX and considering the presence of mutations that might be connected with the temperature-sensitive phenotype $[40,42,43]$.

It is known that for optimal influenza virus replication trypsin addition is crucial. The selection of the trypsin activity depends on the cell line (depending on proteases that are secreted), the medium (protein content), and also the virus strain [44]. Here, for both LAIV strains we tested 3 different concentrations to identify an optimal trypsin activity and found $1 \times 10^{-6}$ units/cell to result in highest titers. The reduced temperature of $33^{\circ} \mathrm{C}$ did not have an effect on the optimal trypsin concentration due to an only slightly impaired enzyme activity at this temperature [34]. However, a design of experiment approach considering trypsin activity and other parameters would be useful for further process optimization [17]. Shaker flask experiments were found to be highly predictive and scale-up to stirred tank bioreactors was possible without further optimization and without loss of productivity. Particularly this easy scaleup provides higher flexibility compared to eggs or adherent cells.

A cell density effect, i.e. reduced titers and productivities at high CCI, as described for HEK293 cells and insect Sf9 cells infected with adenovirus, influenza virus and baculovirus $[21,27,29,30,45]$, was also observed with influenza virus-infected CR.pIX cells. At CCI above a critical concentration of $4 \times 10^{6}$ cells $/ \mathrm{mL}$, cell-specific virus productivity decreased. The same critical cell concentration $\left(4 \times 10^{6}\right.$ cells $\left./ \mathrm{mL}\right)$ was also found in studies 
using A/PR/8/34-infected HEK293 cells [21]. Influenza virus replication is known to modulate the cell cycle to include the cellular environment for replication [46]. We have observed previously that the cell cycle fractions of a CR.pIX population at $8 \times 10^{6}$ cells $/ \mathrm{mL}$ (six days growth) do not differ significantly from the fractions at $2 \times 10^{6}$ cells/ $\mathrm{mL}$, which corresponds to about three days growth (data not shown). For this reason, we focused on medium limitations as a cause for the cell density effect. Addition of a 10fold higher trypsin activity suggests that impaired virus propagation was not due to trypsin inhibitors released by the cells during the growth phase. Furthermore, the depletion of a common medium component also appears unlikely as a medium feed could not rescue virus titers or cell-specific productivities. Supporting this observation, neither the concentrations of the tested amino acids nor metabolites such as glucose or pyruvate appeared to be limiting (data not shown). Still, we cannot rule out that the accumulation of more elusive medium compounds (for example lipids, trace elements or vitamins) may be responsible. Thus, at this moment we speculate that accumulation of inhibiting substances (that we did not measure) may cause the cell density effect. This hypothesis is currently tested in perfusion cultivations where cells are infected at very high cell concentrations. Future studies will also investigate modification of the medium (which was designed for proliferation and compatibility with a biphasic poxvirus production process [25]) to increase not only virus titers and productivity but also the critical CCI.

Our results show that the $c a$ strain A/Singapore can replicate to $1 \times 10^{8}$ virions $/ \mathrm{mL}$ in a CR.pIX cellbased process. This corresponds to approximately 10000 vaccine doses per liter reactor volume assuming that one dose contains $10^{7}$ active virus particles (not taking into account losses during downstream processing). Romanova et al. obtained $2 \times 10^{8} \mathrm{pfu} / \mathrm{mL}$ with the same master donor strain (A/Singapore/1/57 ca) using adherent Vero cells [11]. With adherent MDCK cells, titers for the related strain A/NewCaledonia/20/99 of up to $10^{9} \mathrm{FFU} / \mathrm{mL}$ have been reported $[8,10,14,47]$. Several influenza $B$ strains were also tested in those studies and were produced to titers of $10^{8}$ to $10^{9}$ virions $/ \mathrm{mL}$. As it is generally known that achievable titers are strainspecific, extensive optimizations normally help to maximize titers for each strain. Aggarwal et al. and George et al. have shown in their studies that high titers for $B$ strains can be achieved after extensive optimization of moi, microcarrier concentration, agitation rate and CCI $[10,47]$. Thus, we are confident that additional optimization of CR.pIX cell-based processes (i.e. media and moi optimization) can further improve the propagation of the tested B/Vienna strain.

\section{Conclusions}

Our study provides preliminary evidence for the potential for production of LAIV to high titers in a suspension process with an avian cell line. This process is fast with peak titers already $24 \mathrm{~h}$ post infection and easily scalable to industrial volumes as neither addition of microcarriers nor medium replacements are required. The use of an avian cell line designed specifically for vaccine production and a chemically-defined medium should facilitate regulatory approval. Optimization of medium, feeding or perfusion strategy and process parameters will be pursued to achieve a further increase in $\mathrm{CCI}$ and improvement of virus titers.

\section{Methods \\ Cells}

Suspension CR.pIX cells were routinely cultivated in 150 or $250 \mathrm{~mL}$ vented and baffled shaker flasks (working volume 50 or $150 \mathrm{~mL}$, Corning) at $185 \mathrm{rpm}$ and $5 \mathrm{~cm}$ amplitude or in T175 flasks (working volume $50 \mathrm{~mL}$, Greiner) without agitation. Cultivation conditions were $37^{\circ} \mathrm{C}$ and $5 \% \mathrm{CO}_{2}$ in chemically-defined medium (CD-U2, PAA) supplemented with glutamine, alanine (both $2 \mathrm{mM}$ final concentration, Sigma) and recombinant insulin-like growth factor (LONG-R3 IGF, $10 \mathrm{ng} / \mathrm{mL}$ final concentration, Sigma). Cells were passaged twice a week by dilution with fresh medium.

\section{Virus strains}

Wild type human influenza virus strain H1N1 A/PR/8/34 was received from the Robert Koch Institute (ampoule \#3138) and adapted to growth in MDCK cells. Coldadapted $(c a)$ influenza virus strains were derived by coldadaptation of master donor strains, reassortment with wild-type strains and subsequent adaptation to Vero cell cultures. These steps were done at Polymun Scientific $\mathrm{GmbH}$ according to Romanova et al. [11]. One A and one B strain of these Vero-adapted live attenuated viruses was used in the studies described here: human influenza H1N1 A/Singapore/1/57 ca $\times$ A/Singapore/ 2339/2000 (abbreviated as A/Singapore) and human influenza B/Vienna/1/1999/37 ca $\times$ B/Singapore/548/ 2000 (B/Vienna).

\section{Analytical methods}

Cell concentration and viability were determined with a ViCELL XR device (BeckmanCoulter). Infectious titers $\left(\mathrm{TCID}_{50}\right)$ were measured by titration of supernatants on MDCK monolayers. Samples from A/PR/8/34 experiments were analyzed at $37^{\circ} \mathrm{C}$, whereas samples from LAIV strains were analyzed at $33^{\circ} \mathrm{C}$. Antibodies against the HA protein were purchased from NIBSC institute, namely anti-A/PR/8/34 (NIBSC code \#03/242), antiA/Brisbane/59/2007 (NIBSC code \#08/112) for detection 
of the A/Singapore strain and anti-B/Yamagata/16/88 (NIBSC code \#92/582) for detection of the B/Vienna strain. All primary antibodies were used in a 1:200 dilution. As a secondary antibody we used donkey anti-sheep Alexa488 IgG (Invitrogen) in a 1:500 dilution. TCID $_{50}$ titers (read-out: virions $/ \mathrm{mL}$ ) were calculated according to Spearman and Kärber [48]. Cell-specific virus yield was calculated by dividing the maximal infectious titers (from $\mathrm{TCID}_{50}$ assay) by the maximal viable cell concentration at or after time of infection. Samples from $\mathrm{A} / \mathrm{PR} / 8 / 34$ experiments were additionally quantified by hemagglutination (HA) assay [49].

\section{Adaptation of virus strains to CR.plX cells}

CR.pIX-adapted working virus seeds were produced by passaging the Vero-adapted virus strains in T-flask cultures of CR.pIX cells (CCI $2 \times 10^{6}$ cells $\left./ \mathrm{mL}\right)$ using a moi of $10^{-3}$. Harvests from several passages and time points were titrated and harvests with highest titers were chosen retroactively as seed virus. Adaptation of the $c a$ strains was done at a reduced temperature of $33^{\circ} \mathrm{C}$. CR. pIX-adapted working virus seeds were stored in aliquots at $-80^{\circ} \mathrm{C}$ for all further experiments.

\section{Small-scale infection experiments}

After inoculating $8 \times 10^{5}$ cells $/ \mathrm{mL}$, the cells were grown in shaker or T175 flasks up to $2 \times 10^{6}$ cells $/ \mathrm{mL}$ or highercell concentrations as indicated for the respective experiment. Calculated volumes of virus seed (for moi $10^{-3}$ ) and trypsin stock solution (500 units $/ \mathrm{mL}$ ) for the desired trypsin activity (as indicated for each experiment) were added directly to the cell suspension. In experiments where a complete medium exchange was performed, the whole culture was centrifuged at $150 \times \mathrm{g}$ for $10 \mathrm{~min}$ to collect cells prior to re-suspension in fresh medium. For a partial medium exchange, only half of the culture volume was centrifuged, re-suspended in fresh medium and subsequently pooled with the remaining non-centrifuged culture. Cultures were sampled once or twice per day. Cell concentration and viability were measured immediately; all samples for determination of virus titers $\left(\mathrm{TCID}_{50}\right.$ and $\mathrm{HA}$ yields) were stored at $-80^{\circ} \mathrm{C}$ until analysis of all samples belonging to the same experiment.

\section{Bioreactor infection experiments}

Stirred tank bioreactors (1L working volume, DasGip AG) were inoculated with $8 \times 10^{5}$ cells $/ \mathrm{mL}$. Monitoring and control of cultivations parameters were carried out with the cellferm-pro ${ }^{\circledR}$ system (DasGip AG). Bioreactors were equipped with pitched-blade stirrers operated at $120 \mathrm{rpm}$. The $\mathrm{pO}_{2}$ was set to $50 \%$ by pulsed aeration with air enriched with variable content of $\mathrm{O}_{2}$ and $\mathrm{CO}_{2}$. The $\mathrm{pH}$ value was allowed to drop from 7.4 to 7.0 during the first $72 \mathrm{~h}$ of cell growth and controlled at $\mathrm{pH} 7.0$ afterwards.
Analogous to infection optimization at small scale, cells were grown to the required cell concentration and subsequently infected by adding calculated volumes of A/Singapore virus (for moi $10^{-3}$ ) and a trypsin stock solution (5000 units $/ \mathrm{mL}$ ). Upon infection, cultivation temperature was reduced from $37^{\circ} \mathrm{C}$ to $33^{\circ} \mathrm{C}$. All measurements were performed as described before.

\section{Competing interests}

Patent applications covering avian cell lines (including AGE1.CR.pIX) have been filed by IJ and VS.

\section{Authors' contributions}

$V L$ conceived the experiments and drafted the manuscript. SM conducted the adaptations of cold-adapted influenza virus strains and carried out preliminary experiments. IJ and YG edited the manuscript and participated in planning the experiments. DK and VS participated in designing the study. UR helped in drafting the manuscript and generally supervised the project. All authors read and approved the final manuscript.

\section{Acknowledgements}

The authors thank Claudia Best, Nancy Wynserski, llona Behrendt, and Susanne König for their excellent technical assistance. The advice of Hermann Katinger was highly appreciated.

\section{Author details}

${ }^{1}$ Max Planck Institute for Dynamics of Complex Technical Systems, Sandtorstr. 1, 39106, Magdeburg, Germany. ²ProBioGen AG, Goethestr. 54, 13086, Berlin, Germany. ${ }^{3}$ Polymun Scientific GmbH, Donaustr. 99, 3400, Klosterneuburg, Austria. ${ }^{4}$ University for Applied Sciences, Robert-Gerwig-Platz 1, 78120, Furtwangen, Germany. ${ }^{5}$ Chair of Bioprocess Engineering, Otto-von-Guericke University Magdeburg, Universitätsplatz 2, 39106, Magdeburg, Germany.

Received: 12 June 2012 Accepted: 15 October 2012

Published: 30 October 2012

\section{References}

1. Hancock K, Veguilla V, Lu X, Zhong W, Butler EN, Sun H, Liu F, Dong L, DeVos JR, Gargiullo PM, et al: Cross-reactive antibody responses to the 2009 pandemic H1N1 influenza virus. N Engl J Med 2009, 361(20):1945-1952.

2. Sun K, Ye J, Perez DR, Metzger DW: Seasonal FluMist vaccination induces cross-reactive T cell immunity against H1N1 (2009) influenza and secondary bacterial infections. J Immunol 2011, 186(2):987-993.

3. Tosh PK, Boyce TG, Poland GA: Flu myths: dispelling the myths associated with live attenuated influenza vaccine. Mayo Clinic proceedings Mayo Clinic 2008, 83(1):77-84

4. Clements ML, Betts RF, Tierney EL, Murphy BR: Resistance of adults to challenge with influenza A wild-type virus after receiving live or inactivated virus vaccine. J Clin Microbiol 1986, 23(1):73-76.

5. Carter NJ, Curran MP: Live attenuated influenza vaccine (FluMist(R); Fluenz): a review of its use in the prevention of seasonal influenza in children and adults. Drugs 2011, 71(12):1591-1622

6. Global pandemic influenza action plan to increase vaccine supply: WHO/IVB/ 06.13; http://www.who.int/csr/resources/publications/influenza/ WHO_CDS_EPR_GIP_2006_1/en/index.html.

7. Chen Z, Wang W, Zhou H, Suguitan AL Jr, Shambaugh C, Kim L, Zhao J, Kemble G, Jin H: Generation of live attenuated novel influenza virus A/ California/7/09 (H1N1) vaccines with high yield in embryonated chicken eggs. J Virol 2010, 84(1):44-51.

8. Liu J, Shi X, Schwartz R, Kemble G: Use of MDCK cells for production of live attenuated influenza vaccine. Vaccine 2009, 27(46):6460-6463.

9. Ghendon YZ, Markushin SG, Akopova II, Koptiaeva IB, Nechaeva EA, Mazurkova LA, Radaeva IF, Kolokoltseva TD: Development of cell culture (MDCK) live cold-adapted (CA) attenuated influenza vaccine. Vaccine 2005, 23(38):4678-4684.

10. George M, Farooq M, Dang T, Cortes B, Liu J, Maranga L: Production of cell culture (MDCK) derived live attenuated influenza vaccine (LAIV) in a fully disposable platform process. Biotechnol Bioeng 2010, 106(6):906-917. 
11. Romanova J, Katinger D, Ferko B, Vcelar B, Sereinig S, Kuznetsov O, Stukova M, Erofeeva M, Kiselev O, Katinger $\mathrm{H}$, et al: Live cold-adapted influenza A vaccine produced in Vero cell line. Virus Res 2004, 103(1-2):187-193.

12. Egorov A, Brandt S, Sereinig S, Romanova J, Ferko B, Katinger D, Grassauer A, Alexandrova $G$, Katinger $H$, Muster T: Transfectant influenza A viruses with long deletions in the NS1 protein grow efficiently in Vero cells. J Virol 1998, 72(8):6437-6441.

13. Audsley JM, Tannock GA: The growth of attenuated influenza vaccine donor strains in continuous cell lines. J Virol Methods 2005, 123(2):187-193.

14. Hussain Al, Cordeiro M, Sevilla E, Liu J: Comparison of egg and high yielding MDCK cell-derived live attenuated influenza virus for commercial production of trivalent influenza vaccine: in vitro cell susceptibility and influenza virus replication kinetics in permissive and semi-permissive cells. Vaccine 2010, 28(22):3848-3855.

15. Chu C, Lugovtsev V, Golding H, Betenbaugh M, Shiloach J: Conversion of MDCK cell line to suspension culture by transfecting with human siat7e gene and its application for influenza virus production. Proc Natl Acad Sci USA 2009, 106(35):14802-14807

16. Lohr V, Genzel Y, Behrendt I, Scharfenberg K, Reichl U: A new suspension MDCK cell line cultivated in a fully defined medium in stirred-tank and wave bioreactor. Vaccine 2010, 28(38):6256-6264.

17. Paillet C, Forno G, Kratje R, Etcheverrigaray M: Suspension-Vero cell cultures as a platform for viral vaccine production. Vaccine 2009 27(46):6464-6467.

18. van Wielink R, Kant-Eenbergen HC, Harmsen MM, Martens DE, Wijffels RH, Coco-Martin JM: Adaptation of a Madin-Darby canine kidney cell line to suspension growth in serum-free media and comparison of its ability to produce avian influenza virus to Vero and BHK21 cell lines. J Virol Methods 2011, 171(1):53-60.

19. Doroshenko A, Halperin SA: Trivalent MDCK cell culture-derived influenza vaccine Optaflu (Novartis Vaccines). Expert Rev Vaccines 2009, 8(6):679-688.

20. Cox RJ, Madhun AS, Hauge S, Sjursen H, Major D, Kuhne M, Hoschler K, Saville M, Vogel FR, Barclay W, et al: A phase I clinical trial of a PER.C6 cell grown influenza H7 virus vaccine. Vaccine 2009, 27(13):1889-1897.

21. Le Ru A, Jacob D, Transfiguracion J, Ansorge S, Henry O, Kamen AA: Scalable production of influenza virus in HEK-293 cells for efficient vaccine manufacturing. Vaccine 2010, 28(21):3661-3671.

22. Brown SW, Mehtali M: The Avian EB66(R) Cell Line, Application to Vaccines, and Therapeutic Protein Production. PDA J Pharm Sci Technol / PDA 2010, 64(5):419-425

23. Lohr V, Rath A, Genzel Y, Jordan I, Sandig V, Reichl U: New avian suspension cell lines provide production of influenza virus and MVA in serum-free media: studies on growth, metabolism and virus propagation. Vaccine 2009, 27(36):4975-4982.

24. Jordan I, Vos A, Beilfuss S, Neubert A, Breul S, Sandig V: An avian cell line designed for production of highly attenuated viruses. Vaccine 2009, 27(5):748-756.

25. Jordan I, Northoff S, Thiele M, Hartmann S, Horn D, Howing K, Bernhardt H, Oehmke $\mathrm{S}$, von Horsten $\mathrm{H}$, Rebeski $\mathrm{D}$, et al: A chemically defined production process for highly attenuated poxviruses. Biologicals 2011, 39(1):50-58.

26. Lohr V, Rath A, Jordan I, Sandig V, Genzel Y, Reichl U: Avian Designer Cells AGE1.CR as Candidates for MVA and Influenza Vaccine Production. In Proceedings of the 21st Annual Meeting of the European Society for Animal Cell Technology (ESACT). Edited by Jenkins N, Barron N, Alves P. Dublin, Ireland: SpringerLink; 2009:615-631.

27. Zhang C, Ferreira TB, Cruz PE, Alves PM, Haury M, Carrondo MJT: The importance of 293 cell cycle phase on adenovirus vector production. Enzyme Microb Technol 2006, 39:1328-1332.

28. Bernal V, Carinhas N, Yokomizo AY, Carrondo MJ, Alves PM: Cell density effect in the baculovirus-insect cells system: a quantitative analysis of energetic metabolism. Biotechnol Bioeng 2009, 104(1):162-180.

29. Bedard C, Kamen A, Tom R, Massie B: Maximization of recombinant protein yield in the insect cell/baculovirus system by one-time addition of nutrients to high-density batch cultures. Cytotechnology 1994, 15(1-3):129-138.

30. Meghrous J, Mahmoud W, Jacob D, Chubet R, Cox M, Kamen AA: Development of a simple and high-yielding fed-batch process for the production of influenza vaccines. Vaccine 2009, 28(2):309-316.

31. Ferreira TB, Perdigao R, Silva AC, Zhang C, Aunins JG, Carrondo MJ, Alves PM: 293 cell cycle synchronisation adenovirus vector production. Biotechnol Prog 2009, 25(1):235-243.
32. Petiot $E$, Jacob D, Lanthier $S$, Lohr V, Ansorge S, Kamen AA: Metabolic and kinetic analyses of influenza production in perfusion HEK293 cell culture. BMC Biotechnol 2011, 11:84

33. Bock A, Schulze-Horsel J, Schwarzer J, Rapp E, Genzel Y, Reichl U: Highdensity microcarrier cell cultures for influenza virus production. Biotechnol Prog 2011, 27(1):241-250.

34. Moskvichyov BV, Komanov EV, Ivanova GP: Study of Trypsin Thermodenaturation Process. Enzyme Microb Technol 1986, 8(8):498-502.

35. Feng SZ, Jiao PR, Qi WB, Fan HY, Liao M: Development and strategies of cell-culture technology for influenza vaccine. Appl Microbiol Biotechnol 2011, 89(4):893-902.

36. Genzel Y, Reichl U: Continuous cell lines as production system for influenza vaccines. Expert Rev Vaccines 2009, 8(12):1681-1692.

37. Pau MG, Ophorst C, Koldijk MH, Schouten G, Mehtali M, Uytdehaag F: The human cell line PER.C6 provides a new manufacturing system for the production of influenza vaccines. Vaccine 2001, 19(17-19):2716-2721.

38. Prevention and Control of Influenza: Recommendations of the Advisory Committee on Immunization Practices (ACIP); http://www.cdc.gov/mmwr/ preview/mmwrhtml/rr5408a1.htm.

39. Solorzano A, Ye J, Perez DR: Alternative live-attenuated influenza vaccines based on modifications in the polymerase genes protect against epidemic and pandemic flu. J Virol 2010, 84(9):4587-4596.

40. Chen Z, Aspelund A, Kemble G, Jin H: Molecular studies of temperaturesensitive replication of the cold-adapted B/Ann Arbor/1/66, the master donor virus for live attenuated influenza FluMist vaccines. Virology 2008 380(2):354-362.

41. Katinger $\mathrm{H}$, Egorov A, Ferko B, Romanova J, Katinger D: Live attenuated influenza vaccine; 2009. PCT/EP01/11087; US 7,494,659 B2.

42. Kiseleva I, Su Q, Toner TJ, Szymkowiak C, Kwan WS, Rudenko L, Shaw AR, Youil R: Cell-based assay for the determination of temperature sensitive and cold adapted phenotypes of influenza viruses. J Virol Methods 2004, 116(1):71-78.

43. Chan W, Zhou H, Kemble G, Jin H: The cold adapted and temperature sensitive influenza A/Ann Arbor/6/60 virus, the master donor virus for live attenuated influenza vaccines, has multiple defects in replication at the restrictive temperature. Virology 2008, 380(2):304-311.

44. Steinhauer DA: Role of hemagglutinin cleavage for the pathogenicity of influenza virus. Virology 1999, 258(1):1-20.

45. Carinhas N, Bernal V, Yokomizo AY, Carrondo MJ, Oliveira R, Alves PM: Baculovirus production for gene therapy: the role of cell density, multiplicity of infection and medium exchange. Appl Microbiol Biotechnol 2009, 81(6):1041-1049.

46. He Y, Xu K, Keiner B, Zhou J, Czudai V, Li T, Chen Z, Liu J, Klenk HD, Shu YL, et al: Influenza A virus replication induces cell cycle arrest in G0/G1 phase. J Virol 2010, 84(24):12832-12840.

47. Aggarwal K, Jing F, Maranga L, Liu J: Bioprocess optimization for cell culture based influenza vaccine production. Vaccine 2011, 29(17):3320-3328.

48. Mahy BWJ, Kangro HO: Virology Methods Manual. London: Academic Press Limited; 1996

49. Kalbfuss B, Knochlein A, Krober T, Reichl U: Monitoring influenza virus content in vaccine production: precise assays for the quantitation of hemagglutination and neuraminidase activity. Biologicals 2008, 36(3):145-161.

doi:10.1186/1472-6750-12-79

Cite this article as: Lohr et al:: Live attenuated influenza viruses produced in a suspension process with avian AGE1.CR.pIX cells. BMC Biotechnology 2012 12:79. 